\title{
Knowledge and Practice of Eating Disorders Among a Group of Adolescent Dental Patients
}

\author{
Travis Martin Hicks, DDS
}

A thesis submitted to the faculty of the University of North Carolina at Chapel Hill in partial fulfillment of the requirements for the degree of Master of Science in the Department of Pediatric Dentistry in the School of Dentistry.

\author{
Chapel Hill \\ 2012 \\ Approved by: \\ Michael W. Roberts
}

Jessica Y. Lee

Tung Nguyen

Maria La Via 
C2012

Travis Martin Hicks, DDS

ALL RIGHTS RESERVED 


\section{ABSTRACT \\ TRAVIS HICKS: Knowledge and Practice of Eating Disorders Among a Group of Adolescent Dental Patients (Under the direction of Michael W. Roberts)}

The purpose of this study was to look at a cohort of female adolescent patients between the ages of 12-17 years to ascertain how much they knew about the eating disorders of bulimia and anorexia nervosa, determine if they had practiced behavior consistent with bulimia and/or anorexia nervosa, and compare the individual participant's personal body image to the participant's Body Mass Index (BMI) percentile to determine if there was a disconnect with actual and perceived healthy weight status. A validated survey instrument was self completed by 126 subjects and weight, height, and BMI percentile were obtained for all participants. Based on the response to the validated questions, $18.3 \%$ of the sample may have an eating disorder. The BMI percentiles were higher in the group suspected of having an eating disorder. Of those with a suspected eating disorder, only $38 \%$ could correctly identify the definition/symptoms of bulimia nervosa and $50 \%$ for anorexia nervosa. Educational interventions should be directed at this young age group, as it appears eating disorders are beginning at a very early age. If the at-risk individuals knew more about the disorders and the consequences that accompany them, they may be less likely to practice the behaviors. 
This thesis is dedicated to

my wife Courtney Hicks,

my parents John Hicks and Beverly Smith, my grandparents and Cecil and Mary Fisher, and my sister Leigh Smith

for their unconditional love and support. 


\section{ACKNOWLEDGEMENTS}

To my thesis advisor, Dr. Michael Roberts, for his unwavering support, guidance and motivation throughout this project.

To committee member, Dr. Jessica Lee, for her invaluable support, encouragement and guidance in research technique.

To committee members, Dr. Tung Nguyen and Dr. Maria La Via, for their expertise and support.

To Dr. Ceib L. Phillips for her assistance with statistics.

To Logan Webb for her assistance with information gathering.

To my fellow pediatric dental residents for their moral support and friendship.

This work was supported in part by Healthy Smiles, Healthy Children and 3M ESPE. 


\section{TABLE OF CONTENTS}

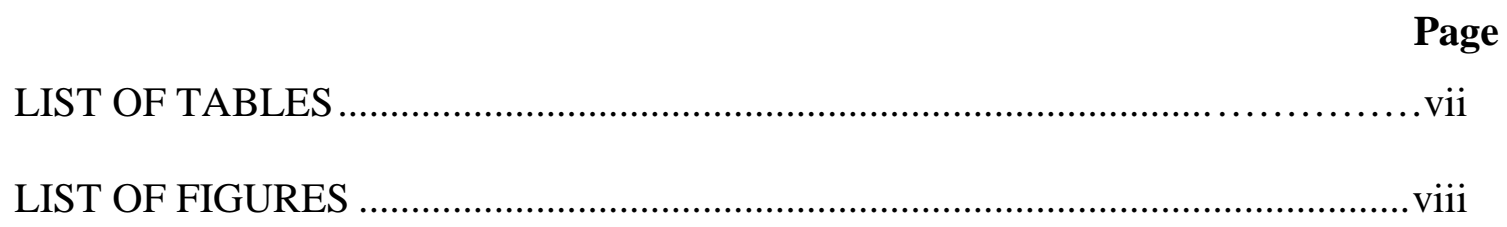

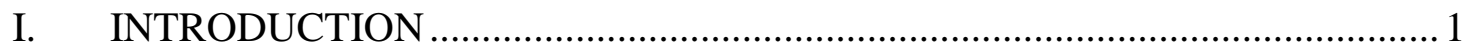

II. REVIEW OF LITERATURE............................................................... 4

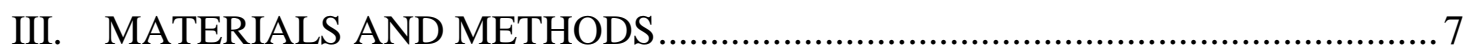

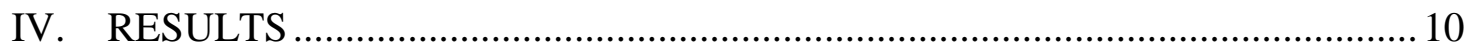

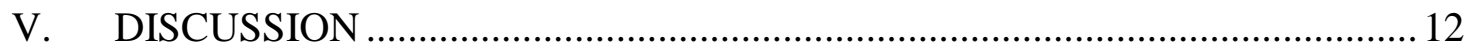

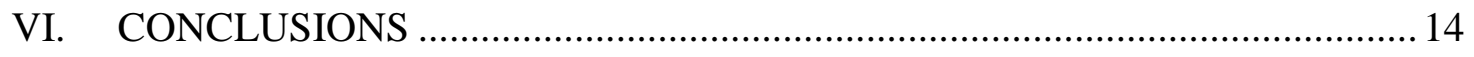

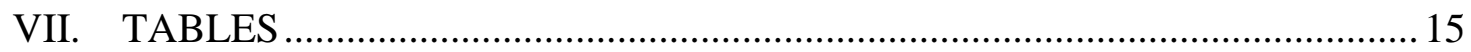

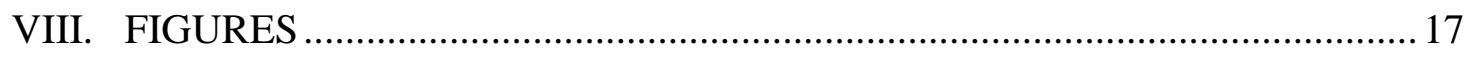

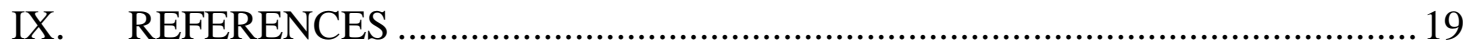




\section{LIST OF TABLES}

Table 1. Responses to SCOFF questions imbedded in the survey..................15

Table 2. Bivariate relationships for behaviors and suspected eating disorder...........16 


\section{LIST OF FIGURES}

Figure 1. The average Body Mass Index (BMI) percentile of the cohort, separated by the suspicion of an eating disorder.

Figure 2. Knowledge of eating disorders .18 


\section{INTRODUCTION}

Eating disorders have a devastating effect on a large number of people. It has been estimated that roughly $8 \%$ of women suffer from either anorexia nervosa or bulimia nervosa. ${ }^{1}$ When these numbers are extrapolated to the general population, 24 million people in the US, and 70 million worldwide, deal with the symptoms of these disorders. ${ }^{2}$ While some men are at risk, these eating disorders are overwhelmingly more prevalent in females with less than $10 \%$ of all cases of anorexia nervosa and bulimia nervosa attributed to males. ${ }^{3,4}$ There is evidence that the number of individuals with eating disorders is increasing. Long term studies have shown an increase in the incidence of anorexia since the 1950s and it is now the third most common chronic illness among adolescents. ${ }^{5,6}$

Depending on the particular type of eating disorder, health problems including diabetes and loss of menses in females, as well as low self-esteem possibly leading to suicide have all been described. ${ }^{7.89}$ The mortality rate of females aged 15-24 with anorexia nervosa has been estimated to be 0.56 percent, 12 times higher than the annual death rate for this age group in the general population. ${ }^{10}$ It has also been found that twenty percent of those suffering from anorexia will prematurely die from complications

linked to the disorder. ${ }^{2}$ There are several oral implications to the diseases as well. Anorexia can lead to oral changes associated with starvation and nutritional deficiencies. ${ }^{11}$ Roberts ${ }^{12}$ found gingival and plaque indexes to be increased in a case study of 47 patients. He reported that depression and distorted self-perception associated 
with anorexia nervosa may explain the lack of good oral hygiene. Bulimia patients often have more severe oral complications. Their diet often contains a high level of sugar and carbohydrates, and chronic vomiting can expose the teeth to an acidic environment leading to enamel erosion patterns (perimolysis). Enlarged salivary glands are also a common finding among bulimic patients. This is often associated with xerostomia, which can contribute to an increase in dental caries. ${ }^{13}$

Eating disorders are not distributed evenly throughout the population. Hoek and van Hoeken ${ }^{3}$ found the prevalence rate for anorexia is highest among females age 15-19, while those with the highest risk for bulimia are females age 20-24. The average age of onset of anorexia is 17 years of age. ${ }^{14}$ Others have found that the age of onset is even younger, with the average age being as low as 14 years of age, and several cases beginning as young as 10 years of age. Young individuals, especially those in the high school age group, are specifically at risk for developing eating disorders due to personal, family, and peer pressures. ${ }^{15}$

While the eating disorders among women have been studied in great detail, less is known about young girls and their knowledge and practices of eating disorders. To better understand this younger age group of females, this study surveyed a cohort of female adolescent patients between the ages of 12-17 years with the specific aims to: 1) ascertain how much they know about the eating disorders of bulimia and anorexia nervosa.

2) determine if they have practiced behavior consistent with bulimia and/or anorexia nervosa. 
3) compare the individual participant's personal body image to the participant's Body Mass Index (BMI) percentile to determine if there is a disconnect with actual and perceived healthy weight status.

The null hypothesis to be tested is that adolescent females do not practice behavior consistent with anorexia nervosa or bulimia nervosa. The second hypothesis is that adolescent females do not know the definition of anorexia nervosa or bulimia nervosa. 


\section{REVIEW OF LITERATURE}

Several studies have assessed lay people's understanding of eating disorders, but most addressed individuals in their twenties and older. ${ }^{16}$ Few studies have looked at adolescents' knowledge about eating disorders and none have looked at children younger than high school age. ${ }^{17}$ Campbell and Roland ${ }^{18}$ have shown that family and peers are usually the first to recognize a medical concern in loved ones, and are the ones who most commonly refer them for medical evaluation. Because peers can be instrumental in the referral process, it is important that adolescents and young adults appreciate and be able to recognize the symptoms of eating disorders. It is also important that adolescents understand what the disorders are so that if they choose to practice these behaviors, they recognize the associated dangers. Because eating disorders begin primarily in young age groups, and is being seen increasingly in even younger children, it is important that we determine this age group's understanding of these particular disorders.

Dental professional's knowledge of the disease has been studied as well. Despite the obvious oral implications of these disorders, it has been shown that dentists are generally not knowledgeable concerning eating disorders and the oral cues that accompany them. In a study of 576 dentists and dental hygienists, Debate ${ }^{19}$ found that more dental hygienists than dentists could identify oral manifestations of eating disorders. She also found that only $16 \%$ of dentists surveyed had a high knowledge of oral cues associated with eating disorders.

While many people suffer from various eating disorders, they often go undiagnosed and untreated. Striegel-Moore ${ }^{20}$ found that only one in ten individuals with an eating disorder receives treatment for it. There may be many reasons for this, 
including the vagueness of the symptoms and the fact that many try to hide their problem from family and friends. Due to oral implications of the disorders, such as perimolysis and high caries rates, dentists and dental hygienists are sometimes the first health providers to become concerned that an eating disorder exists. As a dental practitioner, it is important to be cognizant of eating disorder complications and be prepared to refer for appropriate medical intervention and treatment. ${ }^{6}$

There are various surveys that have been developed to screen patients for eating disorders. One such survey is the "SCOFF (Sick, Control, One stone, Fat, Food) Questionnaire". Modeled after a similar questionnaire for alcoholism, this questionnaire was designed to “...raise suspicion that an eating disorder might exist before rigorous clinical assessment". ${ }^{21}$ The SCOFF questionnaire is intended to be a "simple memorable screening instrument...for non specialists". It has been validated on a group of British females aged 18-50 and it was concluded that "the SCOFF questionnaire detected all cases of anorexia and bulimia nervosa" in the study's sample population. The questionnaire designers stated that it was an “...efficient screening tool for eating disorders." 22

The US equivalent of the SCOFF questionnaire has been developed and was validated in written and verbal form. ${ }^{23,24,25}$ If a patient responds "Yes" to two or more of the five questions, this indicates that an eating disorder of some kind may exist. It includes the following questions:

1. Do you make yourself vomit because you feel uncomfortably full?

2. Do you worry you have lost control over how much you eat?

3. Have you recently lost more than 15 pounds in a three-month period? 
4. Do you believe that you are fat when others say you are too thin?

5. Would you say that food dominates your life? 


\section{MATERIALS AND METHODS}

\section{Study Design and Sample}

This cross sectional study utilized a self completed survey instrument to assess practice behavior consistent with anorexia nervosa or bulimia nervosa in the adolescent female population. Through a power analysis, it was determined that this study would be adequately powered with 125 participants completing the survey. A sample of 126 female study participants was recruited. The study was limited to females because the overwhelming majority of cases with these disorders are found in the female population. Weight, height, and BMI were obtained for all participants. Inclusion criteria consisted of any female orthodontic patient in either the pediatric or orthodontic graduate clinics at the University of North Carolina at Chapel Hill that could speak and read English and were between the ages of 12-17 years of age. Those that were excluded were males, patients that did not fall in this age range, were not a patient in these clinics, or did not speak or read English. The study was approved by the University of North Carolina IRB (\#10-0853) on May 13, 2010.

\section{Sample selection}

Patients that fit the inclusion criteria and their parent(s)/guardian(s) were approached during regularly scheduled orthodontic appointments at the UNC School of Dentistry and asked if they would like to participate in the research study. Both the parent and the clinic patient were given a fact sheet and allowed to ask study personnel questions about the study. If the patient and parent/guardian agreed, the anonymous questionnaire was completed by the patient in private. After completion of the survey, height, weight and BMI were obtained and recorded. There was no follow-up with the patient. 


\section{Questionnaire design}

The survey consisted of 18 questions including ones that addressed knowledge and behaviors associated with eating disorders. The survey instrument was pre-tested on a similar population prior to study initiation. The questionnaire took approximately 5-10 minutes to complete and no identifiable personal information, such as name, SSN, residential address, email address, age, and race were collected during the survey.

Included in the questionnaire were five questions that comprise the "SCOFF Questionnaire". Also included in our questionnaire were items to determine how much the subject knew about the specific eating disorders anorexia nervosa and bulimia nervosa. The study participant was asked to correctly identify the best description of both disorders with multiple choices provided.

\section{Data collection and management}

The questionnaire was distributed to a convenience group of participants who met the inclusion criteria and both the parent(s)/guardian(s) and participant voluntarily agreed to participate in the study. Completion of the survey by the study subject indicated consent to participate in the study. Once the survey was completed, the subject's height and weight were recorded. In an effort to obtain truthful responses, the survey was completed in private. Individual completed surveys contained no personal identifiers and the subject was assured that they will in no way be linked to their answers.

\section{Variable Measurement}

The major explanatory variable was whether the subject practices a behavior consistent with an eating disorder. This was measured by the subject's response of "Yes" or "No" to five questions from the previously validated SCOFF Questionnaire. The 
minor variable was the subject's ability to correctly identify the definition of anorexia nervosa and bulimia nervosa. Other questions were included to help illuminate the individual participant's self body image.

\section{Statistical Analysis}

Our analysis was aimed at determining what percentage of adolescent females in our sample practice a behavior consistent with eating disorders. Two sided $95 \%$ confidence intervals were used to capture this parameter. The subject's BMI were also calculated to determine if the subjects were at a healthy weight. 


\section{RESULTS}

Overall, 126 females completed the survey. The average age was 13.9 years old. Using the SCOFF Questionnaire, 18.3\% of the sample answered "Yes" to two or more questions, indicating an eating disorder may exist. (Table 1) There was no difference in age between the group that answered "Yes" to two or more of the SCOFF questions and the group that did not. Using a 95\% confidence interval, it is believed that the true population of people with a possible eating disorder is between $12-25 \%$. The two most prevalent "Yes" answers were given to the questions asking if they thought they were fat when others didn't and if they had lost control over how much they ate. More than $20 \%$ of the sample responded "Yes" to these questions. The least prevalent "Yes" answer was given for the question regarding vomiting habits, with less than $1 \%$ reporting that they practiced this habit.

Figure 1 displays the age/gender adjusted BMI percentiles for both those with and without a possible eating disorder. The BMI percentiles were higher in the group suspected of having an eating disorder. Based on the standardized scale for adolescent females where a BMI percentile of $85 \%$ to $95 \%$ is considered overweight, the average for the eating disorder group was $87.2 \%$. This is compared to an average BMI percentile of $60.7 \%$ for the non-eating disorder group, which is in the healthy weight range.

Figure 2 shows the subjects ability to correctly identify the best definition for anorexia nervosa and bulimia nervosa. Overall, 63\% correctly identified anorexia nervosa, while slightly more identified bulimia nervosa at $72 \%$. With the use of a ChiSquare test, it becomes apparent that a difference exists between those suspected of an eating disorder and those who are not. (Table 2) Of those with a suspected eating 
disorder, only $38 \%$ could correctly identify bulimia nervosa and $50 \%$ for anorexia nervosa. This is compared to $68 \%$ and $76 \%$ for those without an eating disorder, respectively. Table 2 also shows that those with a suspected eating disorder are much more likely to have discussed their desire to gain/lose weight with someone. This can especially be seen regarding discussions with parents and peers. All of these differences were statistically significant $(\mathrm{p}<0.05)$. 


\section{DISCUSSION}

With over $18 \%$ of the study population answering "Yes" to two or more of the SCOFF questions, it suggests that a high percentage of the group may have an eating disorder. Even with the $12.5 \%$ false positive previously reported ${ }^{21}$, this is an alarmingly high percentage. This is a younger group than what has been previously examined with this survey instrument, and may show that this group of younger females is more at risk for eating disorders than was previously believed. More education may need to be directed at this young age group to help them understand the risks associated with these disorders.

When looking at the individual questions in the SCOFF instrument, a high percentage felt that they were fat and that they had lost control over how much they ate. A low percentage reported vomiting after eating and feeling full. This suggests that the subjects in our study were more at risk for anorexia than bulimia and supports the findings of Hock and van Hoeken. ${ }^{3}$ This may be a factor of the age of the population sampled. It makes sense to even young children that if you do not eat, you will lose weight. It takes more cognitive reasoning usually reached at older ages to understand that if you eat, then vomit, you will lose or not gain weight.

The group suspected of having an eating disorder had a higher BMI percentile on average than the rest of the sample population. The group's average BMI percentile was $87.2 \%$, more than the standardized level of $85 \%$ that is considered to be overweight. The SCOFF survey question asking if the subject believed they were "fat" was the most likely question to be answered "Yes". This group was very cognizant of how they looked and, in a majority of the cases, they were correct in that they were actually overweight. One thing to note is that this group, on average, recognizes when they have a weight problem 
and would be motivated to address the problem. With proper education, hopefully children of this age can learn appropriate ways to achieve and maintain a healthy weight. The eating disorder group was also more likely to discuss the desire to lose weight with others, including parents, friends and other adults. While many adults keep these disorders very private, this study suggests that adolescents suspected of eating disorders do reach out to those close to them. Family and friends should be aware of this and be ready to seek help if a young person discusses weight issues with them.

Overall a majority of the subjects knew about eating disorders and could correctly identify the definition of the disorder. Statistically, fewer subjects suspected of an eating disorder could correctly identify the definitions of anorexia and bulimia nervosa. The subjects identified as possibly having an eating disorder were the ones who knew the least about the disorders. 


\section{CONCLUSIONS}

Young female adolescents are at risk for eating disorders. More education directed at this young age group may be needed. If the at-risk individuals knew more about the disorders and the consequences that accompany them, they may be less likely to practice the behaviors. 
Table 1. Responses to SCOFF questions imbedded in the survey

\section{SCOFF QUESTIONS}

Do you believe that you are fat when others say you are thin?

Do you worry that you have lost control over how much you eat?

Do you make yourself vomit because you feel uncomfortably full?

Would you say that food dominates your life?

Have you recently lost more than 15 pounds in a three-month period?
Yes

$23.4 \%$

$23.2 \%$

$0.8 \%$

$6.4 \%$

$11.1 \%$
No

$76.6 \%$

$76.8 \%$

$99.2 \%$

$93.6 \%$

$88.9 \%$

Two or more "Yes" responses indicates that an eating disorder of some kind may exist.

$18.25 \%$ had two or more "Yes" responses. 
Table 2. Bivariate relationships for behaviors and suspected eating disorder

\begin{tabular}{|c|c|c|c|}
\hline \multirow[t]{2}{*}{ Variable } & \multicolumn{2}{|c|}{ Suspected Eating Disorder } & \multirow[t]{2}{*}{ P-value* } \\
\hline & Yes & No & \\
\hline \multicolumn{4}{|l|}{ Behaviors Measures } \\
\hline $\begin{array}{l}\text { Discussed desire to gain/lose weight with parents } \\
\text { Yes } \\
\text { No }\end{array}$ & $\begin{array}{l}77.2 \% \\
22.7 \%\end{array}$ & $\begin{array}{l}30.1 \% \\
69.9 \%\end{array}$ & $\mathrm{P}<0.05$ \\
\hline $\begin{array}{l}\text { Discussed desire to gain/lose weight with friends } \\
\text { Yes } \\
\text { No }\end{array}$ & $\begin{array}{l}82.6 \% \\
17.4 \% \\
\end{array}$ & $\begin{array}{l}32 \% \\
68 \% \\
\end{array}$ & $\mathrm{P}<0.05$ \\
\hline $\begin{array}{l}\text { Discussed desire to gain/lose weight with another adult } \\
\text { Yes } \\
\text { No }\end{array}$ & $\begin{array}{l}34.8 \% \\
65.2 \% \\
\end{array}$ & $\begin{array}{r}4.9 \% \\
95.2 \% \\
\end{array}$ & $\mathrm{P}<0.05$ \\
\hline $\begin{array}{l}\text { Knows the best definition for bulimia nervosa } \\
\text { Yes } \\
\text { No }\end{array}$ & $\begin{array}{l}38.1 \% \\
61.9 \%\end{array}$ & $\begin{array}{l}68.7 \% \\
31.3 \% \\
\end{array}$ & $\mathrm{P}<0.05$ \\
\hline $\begin{array}{l}\text { Knows the best definition for anorexia nervosa } \\
\text { Yes } \\
\text { No }\end{array}$ & $\begin{array}{l}50 \% \\
50 \% \\
\end{array}$ & $\begin{array}{l}76.3 \% \\
23.7 \%\end{array}$ & $\mathrm{P}<0.05$ \\
\hline
\end{tabular}

*Chi-Square Test 
Figure 1. The average Body Mass Index (BMI) percentile of the cohort, separated by the suspicion of an eating disorder.

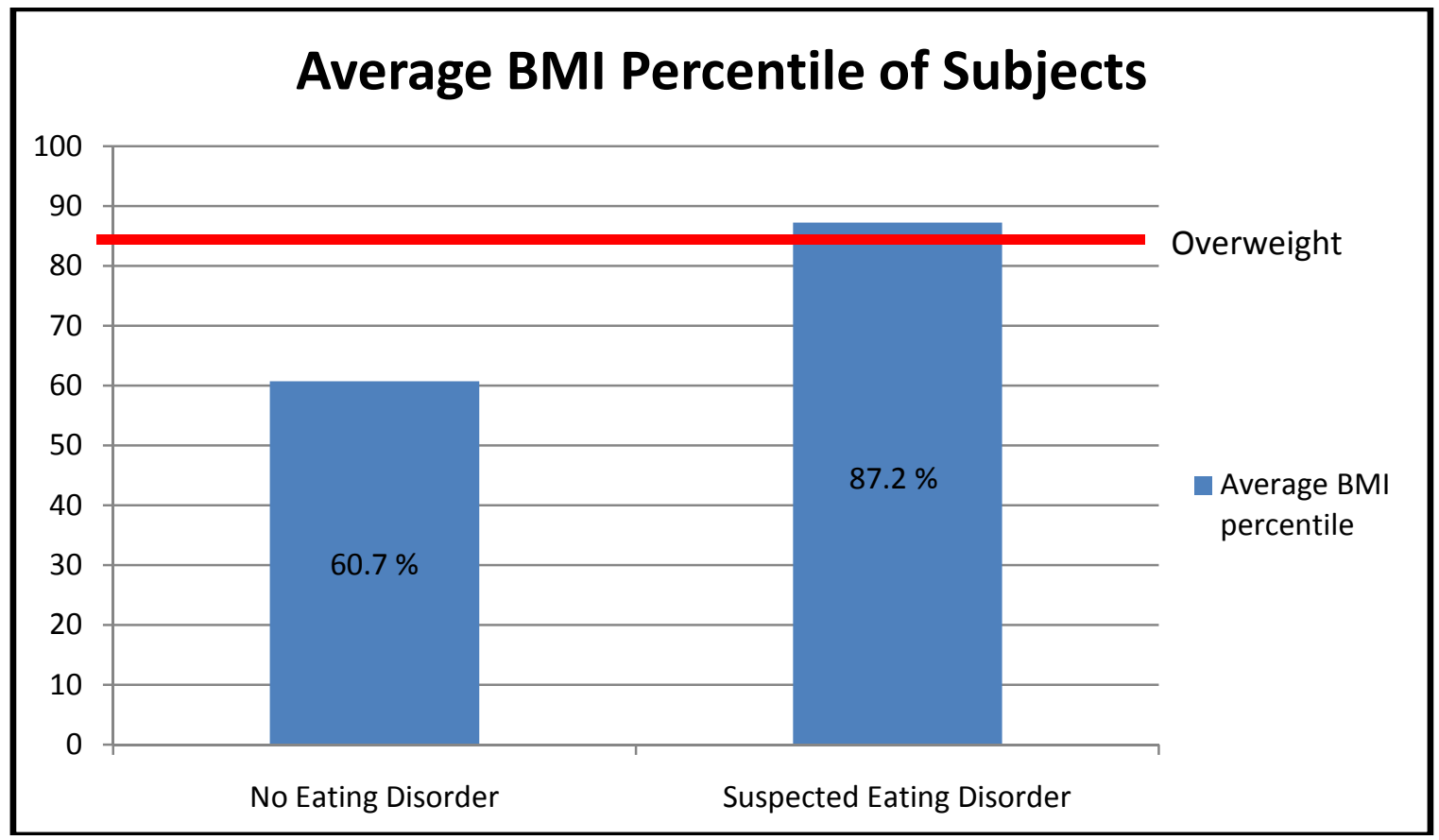


Figure 2. Knowledge of eating disorders

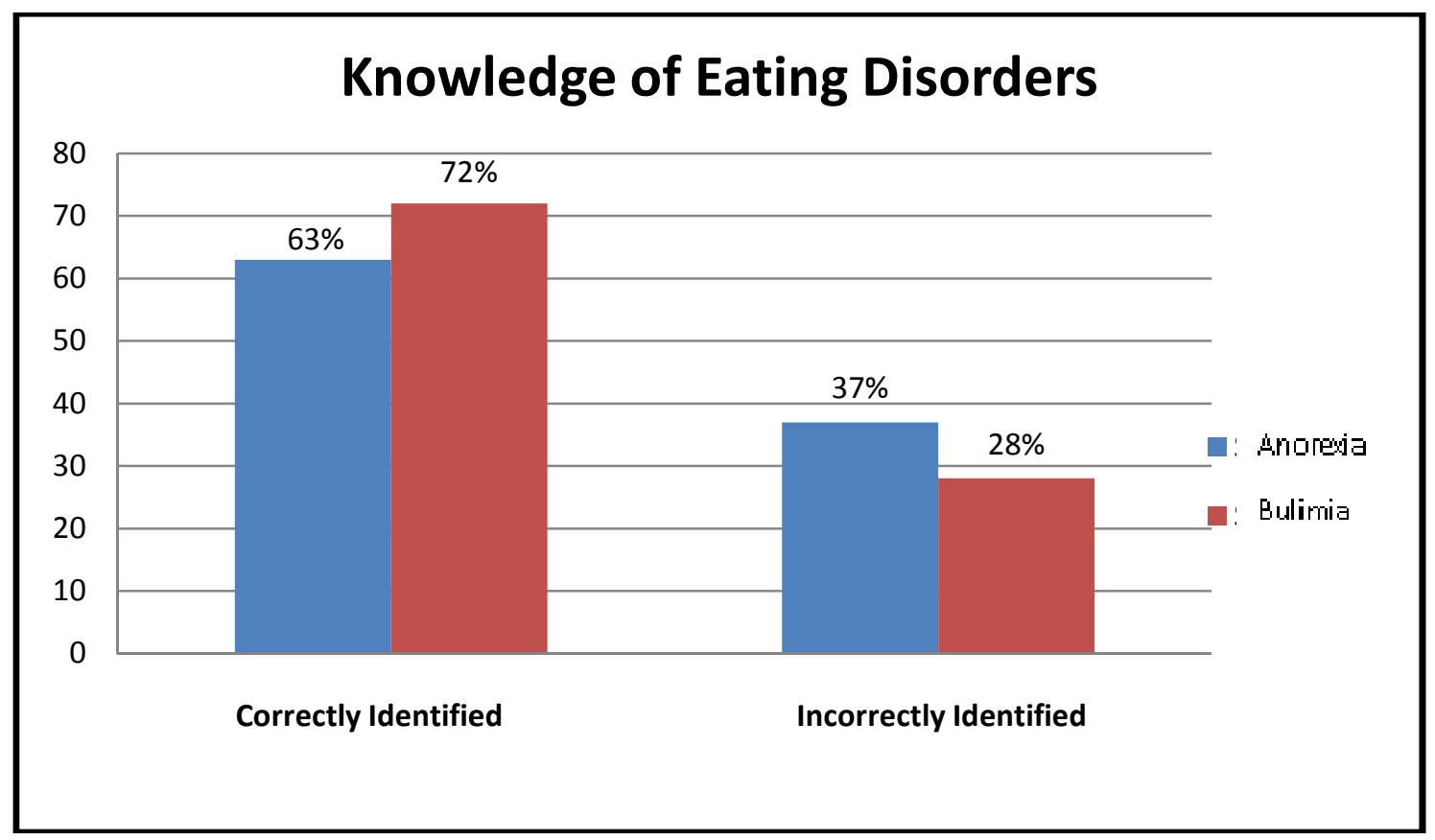




\section{REFERENCES}

1. American Psychiatric Association Work Group on Eating Disorders. Practice guideline for the treatment of patients with eating disorders (revision). Am J Psychiat 2000; 157:1-39.

2. The Renfrew Center Foundation for Eating Disorders. Eating Disorders 101 Guide: A Summary of Issues, Statistics and Resources. Available at: "http://www.renfrewcenter.com/uploads/resources/1067338472_1.doc". Accessed August 9, 2011.

3. Hoek HW, Bartelds AIM, Bosveld JJF, van der Graaf Y, Limpens VEL, Maiwald M, Spaaij CJK. Impact of urbanization on detection rates of eating disorders. Am J Psychiat 1995; 152:1272-1278

4. Garfinkel PE, Lin E, Goering C, Spegg D, Goldbloom D, Kennedy S, Kaplan A, Woodside DB. Bulimia nervosa in a Canadian community sample: prevalance and comparison of subgroups. Am J Psychiat 1995; 152:1052-58.

5. Hoek HW, van Hoeken D. Review of the prevalence and incidence of eating disorders. Int J Eat Disorder 2003; 34:383-396.

6. Public Health Service's Office in Women's Health, Eating Disorders Information Sheet, 2000. Available at: " http://www.anad.org/get-information/about-eatingdisorders/eating-disorders-statistics/". Accessed November 28, 2011

7. Milos G, Spindler A, Hepp U, Schnyder U. Suicide attempts and suicidal ideation: links with psychiatric comorbidity in eating disorder subjects. Gen Hosp Psychiat 2004; 26:129-135.

8. Johnson JG, Spitzer RL, Williams JBW. Health problems, impairment and illness associated with bulimia nervosa and binge eating disorder among primary care and obstetric gynaecology patients. Psychol Med 2001; 31:1455-1466.

9. Kreipe RE, Mou, SM. Eating disorders in adolescents and young adults. Obstet Gyn Clin N Am 2000; 27:101-124.

10. Sullivan PF. Mortality in anorexia nervosa. Am J Psychiat 1995; 152:1073-4.

11. Lo Russo L, Campisi G, Di Fede O, Di Liberto C, Panzarella V, Lo Muzio L. Oral manifestations of eating disorders: a critical review. Oral Dis 2008; 14:479-484.

12. Roberts MW, Li S-H. Oral findings in anorexia nervosa and bulimia nervosa: as study of 47 cases. JADA 1987; 115:407-410.

13. Little JW. Eating disorders: Dental implications. Oral Surg Oral Med O 2002; 93:138-143. 
14. American Psychiatric Association (APA), 1994. Diagnostic and Statistical Manual of Mental Disorders, 4th ed. Washington, D.C., American Psychiatric Association.

15. Cavanaugh CJ, Lemberg R. What we know about eating disorders: facts and statistics. In Lemberg R, Cohn, L, eds. Eating Disorders: A reference sourcebook. Phoenix: Oryx Press; 1999.

16. Hunt, J, Rothman AJ. College students' mental models for recognizing anorexia and bulimia nervosa. Appetite 2007; 48:289-300.

17. D'Souza MC, Forman SF, Austin SB. Follow-up evaluation of a high school eating disorders screening program: knowledge, awareness and self-referral. J Adolescent Health 2005; 36:208-13.

18. Campbell SM, Roland MO. Why do people consult the doctor? Fam Pract 1996; 13:75-83.

19. DeBate RD, Tedesco LA, and Kerschbaum WE. Knowledge of oral and physical manifestations of anorexia and bulimia nervosa among dentists and dental hygienists. J Dent Educ 2005; 69:346-354.

20. Striegel-Moore R, Leslie D. One year use and cost of inpatient and outpatient services among female and male patients with an eating disorder: evidence from a national database of insurance claims. Int J Eat Disorder 2000; 27:381-389.

21. Morgan JF, Reid F, Lacey JH. The SCOFF questionnaire: assessment of a new screening tool for eating disorders. Brit Med J 1999; 319:1467-1468.

22. Luck A, Morgan J, Luck JF, Reid F, O'Brien A, Brunton J, Price C, Perry L, Hubert Lacey J. The SCOFF questionnaire and clinical interview for eating disorders in general practice: comparative study. Brit Med J 2002; 325:755-756.

23. Mond JM, Myers TC, Crosby RD, Hay, PJ, Rodgers B, Morgan JF, Lacey JH, Mitchell JE. Screening for eating disorders in primary care: EDE-Q versus SCOFF. Behav Res Ther 2008; 46:612-622.

24. Perry L, Morgan J, Reid F, Brunton, J, Obrien A, Luck A, Lacey H. Screening for symptoms of eating disorders: Reliability of the SCOFF screening tool with written compared to oral delivery. Int J Eat Disorder 2002; 32: 466-472.

25. Parker SC, Lyons J, Bonner J. Eating disorders in graduate students: Exploring the SCOFF questionnaire as a simple screening tool. J Am Coll Health 2005; 2: 103-107. 